\title{
Gene Expression of
} Metalloproteinases and Endogenous Inhibitors in the Lamellae of Dairy Heifers With Oligofructose-Induced Laminitis

\section{OPEN ACCESS}

Edited by:

Tracy Stokol,

Cornell University, United States

Reviewed by:

Samuel Black,

University of Massachusetts Amherst,

United States

Andrew Van Eps,

University of Pennsylvania,

United States

*Correspondence:

Hongbin Wang

hbwang1940@neau.edu.cn

Specialty section:

This article was submitted to Veterinary Experimental and

Diagnostic Pathology,

a section of the journal

Frontiers in Veterinary Science

Received: 22 August 2020 Accepted: 02 December 2020 Published: 23 December 2020

Citation:

Ding J, Shi M, Wang L, Qi D, Tao Z,

Hayat MA, Liu T, Zhang J-t and Wang $H$ (2020) Gene Expression of

Metalloproteinases and Endogenous Inhibitors in the Lamellae of Dairy Heifers With Oligofructose-Induced Laminitis. Front. Vet. Sci. 7:597827. doi: 10.3389/fvets.2020.597827

\author{
Jiafeng Ding ${ }^{1,2}$, Mingxian Shi 1,2, Long Wang ${ }^{1,2}$, Dongdong Qi ${ }^{1,2}$, Ze Tao ${ }^{1,2}$, \\ Muhammad A. Hayat ${ }^{1,2}$, Tao Liu ${ }^{1,2}$, Jian-tao Zhang ${ }^{1,2}$ and Hongbin Wang ${ }^{1,2 *}$ \\ ${ }^{1}$ Department of Veterinary Surgery, Northeast Agricultural University, Harbin, China, ${ }^{2}$ Heilongjiang Key Laboratory for \\ Laboratory Animals and Comparative Medicine, Harbin, China
}

Bovine laminitis leads to huge economic losses and animal welfare problems in the dairy industry worldwide. Numerous studies suggested that several metalloproteinases (MPs) may play vital roles in the failure of epidermal attachment. To the best of our knowledge, the present study is the first to investigate and characterize the gene-level changes in distinct MPs and endogenous inhibitors using oligofructose (OF)-induced bovine laminitis model. The objective of this study was to determine aberrant MPs and related inhibitors of bovine laminitis in gene level, and to provide reasonable directions for the further protein-level research. Twelve normal Chinese Holstein dairy heifers were randomly divided into treatment group $(n=6)$ and control group $(n=6)$. The heifers in the treatment group were administered with OF solutions at a dose of 17 $\mathrm{g} / \mathrm{kg}$ of body weight via a stomach tube. The heifers were then humanely euthanized when they met the criteria of bovine laminitis. The heifers in the control group were administered with deionized water at a dose of $2 \mathrm{~L} / 100 \mathrm{~kg}$ of body weight. They humanely euthanized at $72 \mathrm{~h}$. The gene expressions of MPs and endogenous inhibitors, namely, matrix metalloproteinases (MMPs), A disintegrin and metalloproteinases (ADAMs), and A disintegrin and metalloproteinase with thrombospondin motifs (ADAMTs), and tissue inhibitors of metalloproteinases (TIMPs) in the lamellae from two groups were determined via real-time quantitative PCR. The gene expressions of MMP-2, MMP-9, ADAMTS-4, and ADAMTS-5 significantly increased $(P<0.05)$, whereas that of TIMP-2 significantly decreased $(P<0.05)$ in the treatment group relative to the control group. No significant difference was found in the gene expressions of ADAM-10, ADAM-17, TIMP-1, and TIMP-3. These results indicated that the gene-level imbalanced condition of MPs and their TIMPs may be the basic cause for the failure of epidermal attachment. At the same time, more detailed protein-level studies would be needed to further clarify the roles of MPs and TIMPs in the pathogenesis of bovine laminitis, especially to MMP-2, MMP-9, ADAMTS-4, ADAMTS-5, TIMP-2 as well as related substrates (e.g., aggrecan and versican).

Keywords: bovine laminibovine laminitis, pathogenesis, metalloproteinase, TIMP, real-time quantitative PCR, oligofructose overload model 


\section{INTRODUCTION}

Bovine laminitis results in huge economic losses and animal welfare problems in the dairy industry worldwide $(1,2)$. This disease may lead to several laminitis-related claw horn disruptions (CHDs), such as sole ulcer, sole hemorrhage, and white line disease (3). Moreover, it can compromise the structural integrity of lamellae, which are composed of two interdigitating layers, dermal lamellae and epidermal lamellae (4). The lamellae connect the third phalanx (P3) to the inner hoof wall within the capsule. The partial or complete separation of dermal and epidermal lamellae leads to rotation and sinking of the P3 within the capsule, as well as severe pain and lameness (5). The interface of the two layers is basement membrane (BM), which is a vital part of extracellular matrix (ECM). The BM destruction and separation was characteristic histological lesions that mainly cause the failure of epidermal attachment in bovine laminitis (6, 7). However, the related molecular mechanism remains unclear.

In clinical practice, bovine laminitis is typically secondary to several inflammatory diseases, including metritis, Gram-negative pleuropneumonia, and ruminal acidosis (8). Experimental models of bovine laminitis have been built by mimicking these clinical conditions. The oligofructose (OF) overload model is more reliable and more intensively utilized than the other induction models $(9,10)$. The OF-induced models could exhibit the typical characteristic pathophysiological and histological changes as in clinical cases of bovine laminitis $(11,12)$. Until now, the OF-induced laminitis model has been fully utilized in multiple studies of equine laminitis, but less in the bovine laminitis $(13,14)$.

Previous studies reported that several MPs play a critical role in the pathogenesis of equine laminitis, especially in BM destruction and ECM remodeling (15-17). Researchers speculated that MPs may also contribute to bovine laminitis $(18,19)$. However, the MP events has not been investigated in bovine laminitis thus far. In the present study, we firstly determined three classes of MPs and their endogenous inhibitors. The first class of MPs is the classical matrix metalloproteinase (MMP) family, which can degrade various ECM components, especially distinct types of collagens, gelatin, and lamin (20). The second class of MPs is the A disintegrin and metalloproteinase (ADAM) family, especially ADAM-10 and ADAM-17, which are known as "molecular scissors" because they participate in the proteolytic cleavage, or shedding, of the extracellular regions of other transmembrane proteins; hence, they have important roles in the immune system and inflammatory response (21). The last class of MPs is the A disintegrin and metalloproteinase with thrombospondin motifs (ADAMTS) family, which can degrade the structural proteoglycans of cartilage, thus resulting in osteoarthritis (22). Under physiological conditions, these MPs are tightly regulated by specific tissue inhibitors of metalloproteinase (TIMP) to maintain the homeostasis of proteolytic activity of the target tissue (23).

We used an established the OF-induced bovine laminitis model to determine the gene expressions of representative MPs, namely, MMPs, ADAMs, and ADAMTSs, and their specific TIMPs in the lamellae of laminitic heifers. To the best of our knowledge, the present study is the first to investigate and characterize gene-level changes in distinct MPs and endogenous inhibitors using oligofructose (OF)-induced bovine laminitis model. The objective of this study was to determine aberrant MPs and related inhibitors of bovine laminitis in gene level, and to provide reasonable directions for the further proteinlevel research. Besides, these findings could provide theoretical basis for the future selection of valuable therapeutic targets for this disease.

\section{MATERIALS AND METHODS}

\section{Ethics Statement}

The protocols of this study were approved by the Animal Ethics Committee of the Northeast Agricultural University (Harbin, Heilongjiang, China). All experimental animals were continuously monitored by investigators to meet the requirements of Animal Welfare Act (2001) (Permission number: SRM-13).

\section{Experimental Animals}

A total of 12 Chinese Holstein dairy heifers were utilized in this study. Their average age, average body weight, and average body condition score (24) was $20.67 \pm 3.01$ months, $379.71 \pm$ $19.77 \mathrm{~kg}$, and $3.00 \pm 0.23$, respectively. Before buying them from the Wandashan Dairy Farm (Harbin, Heilongjiang, China), each heifer was carefully examined by routine blood and biochemical tests to ensure that they were clinically healthy and exhibited normal locomotion and posture without any CHDs.

Before acclimation, the claws of all heifers were uniformly trimmed. During the 30-day acclimation period, the heifers were housed in a large animal experimental barn with sufficient water and grass hay supply (7.5\% total water-soluble sugar content). The heifers were then trained to accept clinical examinations. After acclimation, the heifers could be led to walk and trot normally by hand and agreed to be examined without any discomfort.

\section{Model Induction}

All heifers were randomly divided into a treatment group $(n=6)$ and a control group $(n=6)$. Before induction, a $0.85 \mathrm{~g} / \mathrm{kg}$ dose of OF (98\% purity; Bailong Biotech, Inc., Dezhou, Shandong, China) was dissolved into warm deionized water $(0.1 \mathrm{~L} / 100 \mathrm{~kg})$, then administered to the heifers in the treatment group via a stomach tube twice daily for 3 days (10). Afterwards, similar methods were utilized, a $17 \mathrm{~g} / \mathrm{kg}$ dose of OF was dissolved into warm deionized water $(2 \mathrm{~L} / 100 \mathrm{~kg})$, and administered to these heifers via a stomach tube. The heifers in the control group were administered with $2 \mathrm{~L} / 100 \mathrm{~kg}$ warm deionized water only by the same method.

Locomotion assessment and hoof testing were performed at $-72,0$ (administration time), 6, 12, 18, 24, 36, 48, 60, and $72 \mathrm{~h}$. Before the locomotion assessment, five licensed veterinarians were carefully trained by watching videos of bovine lameness. They were also required to take lameness-scoring examinations to meet the requirements of this study. During the assessment, all heifers were led by the same investigator to walk and trot along 
TABLE 1 | Locomotion scoring system of dairy cows based on Sprecher et al. (25).

\begin{tabular}{|c|c|c|}
\hline $\begin{array}{l}\text { Lameness } \\
\text { score }\end{array}$ & Description & Assessment criteria \\
\hline 1 & Normal & $\begin{array}{l}\text { Heifer stands and walks with a level-back } \\
\text { posture. Its gait is normal }\end{array}$ \\
\hline 2 & $\begin{array}{l}\text { Mildly } \\
\text { lame }\end{array}$ & $\begin{array}{l}\text { Heifer stands with level-back posture but walks } \\
\text { with an arched-back posture. Its gait is normal }\end{array}$ \\
\hline 3 & $\begin{array}{l}\text { Moderately } \\
\text { lame }\end{array}$ & $\begin{array}{l}\text { Heifer stands and walks with an arched-back } \\
\text { posture. Its gait develops a short-striding step } \\
\text { with one or more limbs }\end{array}$ \\
\hline 4 & Lame & $\begin{array}{l}\text { Heifer stands and walks with an evident } \\
\text { arched-back posture. Its gait develops a } \\
\text { deliberate step at a time. Heifer favors one or } \\
\text { more limbs/feet }\end{array}$ \\
\hline 5 & Severely lame & $\begin{array}{l}\text { Heifer demonstrates an inability or extreme } \\
\text { reluctance to bear weight on one or more of its } \\
\text { limbs/feet }\end{array}$ \\
\hline
\end{tabular}

a straight line or a small circle on the same ground. Meanwhile, they were blindly scored by the trained veterinarians according to a 5-point scoring system (Table 1) (25). When a heifer got a score of $\geq 2$ from all veterinarians, it was considered lame. During the hoof testing, a hoof tester was applied on the junction of the axial sole-bulb and at central site of the dorsoabaxial claw wall in four front claws. A suitable pressure was then applied onto the claws to assess the heifers' attempts to withdraw their legs. Their reactions were subjectively classified as none, slight, or marked.

Following the recommendations of previous studies, supportive therapy was provided to the heifers in the treatment group to ensure their welfare and allow comparison of the results with those of previous studies (10). Ringer's acetate (dose of $15 \mathrm{~mL} / \mathrm{kg}$ of body weight; Heping Animal Medicine, Inc., Harbin, China) and sodium bicarbonate $(84 \mathrm{~g} / \mathrm{L}$, at a dose of $1.5 \mathrm{~mL} / \mathrm{kg}$ of body weight; Heping Animal Medicine, Inc., Harbin, China) were quickly administered via jugular infusion at 18 and $24 \mathrm{~h}$. Calcium borogluconate $(14 \mathrm{mg} \mathrm{Ca} / \mathrm{mL}$, at a dose of $1.4 \mathrm{~mL} / \mathrm{kg}$ of body weight; Heping Animal Medicine, Inc., Harbin, China) was slowly administered via jugular infusion at $18 \mathrm{~h}$.

\section{Sample Acquisition}

On the basis of the accepted criteria for diagnosing bovine laminitis, a heifer in the treatment group that scored $\geq 2$ in the locomotion assessment and showed consecutive painful reactions in the same claw was humanely euthanized $(9,10,26)$. The heifers in the control group were humanely euthanized at $72 \mathrm{~h}$. The lame front limb was rapidly disarticulated from the metacarpophalangeal joint. Several tissue blocks, which consisted of the P3, lamellae tissues, and the central regions of the dorsoabaxial claw wall, were harvested using a band saw. Afterward, the lamellae $\left(\sim 1 \mathrm{~cm}^{2}\right)$ were rapidly dissected from the tissue blocks using a lancet (11). Finally, partial samples were immediately frozen in liquid nitrogen and later stored at $-80^{\circ} \mathrm{C}$.

\section{Physiological Parameter Measurement}

The basic physiological parameters, including heart rate, rectal temperature, respiratory rate, and the $\mathrm{pH}$ value of rumen liquid, were measured in the heifers from both groups at $-72,0$, $6,12,18,24,36,48,60$, and $72 \mathrm{~h}$. Heart rate was recorded using a STAR 8000E patient monitor (Coman Medical Device, Shenzhen, Guangdong, China) three times, and then its mean value was calculated. Rectal temperature was taken using an MC246 electronic thermometer (Omron, Dalian, Liaoning, China) inserted into the anus. Respiratory rate was determined by observing chest and abdominal contraction and relaxation by three investigators, and then its mean value was computed. The $\mathrm{pH}$ value of rumen liquid was measured using an $\mathrm{HI} 9125 \mathrm{pH}$ meter (Hanna Instruments, Vinsokitt, Rhode Island, USA).

\section{RNA Isolation and cDNA Synthesis}

Total RNA was extracted from the lamellae of the 12 heifers by using the Absolutely RNA Miniprep kit (Stratagende, Inc., LaJolla, CA, USA) according to the manufacturer's instructions. The extracted RNA concentration was measured using a Nanodrop 1000UV-Vis spectrophotometer (Thermo Scientific, Waltham, MA, USA). The absorption rations of all samples met 1.95-2.05 (OD 260/OD 280) and over 2.00 (OD 260/OD 230), indicating high RNA purity. The integrity of RNA samples was verified by $1 \%$ agarose gel electrophoresis (Bio-rad Laboratories, Hercules, CA, USA). The concentration of RNA samples was adjusted to $1 \mu \mathrm{g} / \mu \mathrm{L}$ by measuring optical density. Total RNA $(1 \mu \mathrm{g})$ was reverse-transcribed using the PrimeScriptTM RT reagent kit with gDNA eraser (Takara, Dalian, Liaoning, China) following the manufacturer's protocols. Complementary DNA (cDNA) was then diluted with DNase/RNase free water (dilution rate: 1:4) (Takara, Dalian, Liaoning, China) and stored at $-20^{\circ} \mathrm{C}$.

\section{Real-Time Quantitative PCR (qPCR)}

The primer sets utilized in this study were designed to recognize and amplify conserved nucleotide sequences encoding related bovine MPs and TIMPs. The primers used for housekeeping genes ( $\beta$-actin, GAPDH, and UXT) were referred from previous studies $(27,28)$. Primers for MMP-2, MMP-9, ADAM-10, ADAM-17, ADAMTS-1, ADAMTS-4, ADAMTS-5, TIMP-1, TIMP-2, and TIMP-3 were designed using the Primers 5 software (White Institute, Cambridge, MA, USA). The specificity of selected primer sequences was verified using the BLAST computer program from the National Center for Biotechnology Information database (Bethesda, Maryland, USA).

Real-time quantitative PCR (RT-qPCR) was performed using the LightClycler 480 RT-PCR system (Roche, Indianapolis, Indiana, USA) with fluorescence detection of SYBR Premix Ex TaqTM II (Takara, Dalian, Liaoning, China). The PCR mixture $(20 \mu \mathrm{L})$ consisted of $2 \mu \mathrm{L}$ sample cDNA and $18 \mu \mathrm{L}$ PCR master mix. Thereafter, the PCR master mix contained $1.6 \mu \mathrm{L}$ of mixed primer solutions $(10 \mu \mathrm{M}$ each of forward and reverse primers), $6.4 \mu \mathrm{L}$ DNase/RNase free water, and $10 \mu \mathrm{L}$ SYBR green dye. Amplification conditions were set by the classic four-step method: denaturation of temple DNA at $95^{\circ} \mathrm{C}$ for $1 \mathrm{~min} ; 40$ cycles of amplification (quantification analysis model) at $95^{\circ} \mathrm{C}$ for $5 \mathrm{~s}$ and $60^{\circ} \mathrm{C}$ for $1 \mathrm{~min}$; one cycle of melting (melting curve analysis 
model) at $95^{\circ} \mathrm{C}$ for $5 \mathrm{~s}, 60^{\circ} \mathrm{C}$ for $1 \mathrm{~min}$, and then at $95^{\circ} \mathrm{C}$; and one cycle of cooling at $50^{\circ} \mathrm{C}$ for $30 \mathrm{~s}$. All measurements were performed in triplicate.

The values of cycle threshold $(\mathrm{Ct})$ crossing were calculated using the Light Cycler 480 software (version 1.5.0; Roche, Indianapolis, IN, USA). All amplified cDNA products were verified by $1 \%$ gel electrophoresis and melting curve analysis. Template DNA (10-fold serial dilution) was used to generate standard curves and calculate the efficiency for each PCR reaction (Table 2). A reverse-transcription negative blank of each sample and a no-template blank were utilized as negative controls. The $\mathrm{Ct}$ value of each targeted mRNA was normalized to the geometric mean of three housekeeping genes, and the data were calculated according to the $2^{-\Delta \Delta \mathrm{Ct}}$ method and considering quantitative PCR efficiency $(19,28,29)$.

\section{Data Analysis}

Data analysis was performed using GraphPad Prism software (version 7.04; GraphPad Software, Inc., San Diego, CA, USA).
According to the results of D'Agostino and Pearson and ShapiroWilk normality tests, the data of physiological parameters (i.e., heart rate, rectal temperature, respiratory rate, and the $\mathrm{pH}$ value of rumen liquid) fulfilled the assumption of a Gaussian distribution. The data were analyzed by two-way ANOVA (Bonferroni's multiple comparisons test for the treatment and control groups within a time point; Tukey's multiple comparisons test for the treatment group relative to the baseline value [time $0]$ ). Similarly, the data of relative gene expression fulfilled the assumption of a Gaussian distribution according to the results of Shapiro-Wilk normality test. The data were analyzed by Student's $t$-test. In this study, $P<0.05$ was considered significant. All data are presented as mean \pm standard deviation (SD).

\section{RESULTS}

\section{Clinical Manifestations and Physiological Data}

The heifers in the treatment group developed evident symptoms of acute rumen acidosis and systemic inflammatory response

TABLE 2 | Gene, sequence, amplification size, and efficiency of the primers used for RT-qPCR.

\begin{tabular}{|c|c|c|c|c|c|}
\hline Gene & Polarity & Sequence $\left(5^{\prime} \rightarrow 3^{\prime}\right)$ & Size (bp) & Efficiency (\%) & GenBank ID \\
\hline \multicolumn{6}{|c|}{ Matrix metalloprotease (MMP) } \\
\hline MMP-2 & Forward & GCTGTGTACGAAGACCCACA & 289 & 96 & NM_174745.2 \\
\hline \multirow[t]{2}{*}{ MMP-9 } & Forward & GGGTAAGGTGCTGCTGTTCA & 136 & 105 & NM_174744.2 \\
\hline & Reverse & CTGAAAGATGTCGTGCGTGC & & & \\
\hline ADAM-10 & Reverse & GCACAGGTACACTCCTCCAA & & & \\
\hline \multirow[t]{2}{*}{ ADAM-17 } & Forward & AGTCACGGAGGTGTTTGTCC & 193 & 91 & XM_010810303.3 \\
\hline & Reverse & CACATTCCGCCAGACCATCT & & & \\
\hline \multicolumn{6}{|c|}{ A disintegrin and metalloprotease with thrombospondin motifs (ADAMTS) } \\
\hline ADAMTS-1 & Forward & CAGACCGACAAGGAGCACTT & 147 & 97 & NM_001101080.1 \\
\hline \multirow[t]{2}{*}{ ADAMTS-5 } & Forward & CACAAAGGTGGTCGGAACCT & 120 & 95 & NM_001166515.1 \\
\hline & Reverse & AATCTGGTCTGGTCCTTGGC & & & \\
\hline \multicolumn{6}{|c|}{ Tissue inhibitors of metalloprotease (TIMP) } \\
\hline \multirow[t]{2}{*}{ TIMP-1 } & Forward & GGCCTTCTGCAACTCCGAT & 133 & 106 & XM_005228099.2 \\
\hline & Reverse & ATCCCTCAAGGCACTGAACC & & & \\
\hline \multirow[t]{2}{*}{ TIMP-2 } & Forward & GATCCGAGCCAAGGTGGTAG & 111 & 97 & NM_174473.4 \\
\hline & Reverse & TGGGGCATCTTGGTGAATCC & & & \\
\hline \multirow[t]{2}{*}{ TIMP-3 } & Forward & TGATCCGAGCCAAGGTGGTA & 111 & 93 & NM_174473.5 \\
\hline & Reverse & GGGGCATCTTGGTGAATCCT & & & \\
\hline \multicolumn{6}{|c|}{ Housekeeping gene } \\
\hline ACTB & Forward & ACTTGCGCAGAAAACGAGAT & 123 & 97 & NM_173979.3 \\
\hline
\end{tabular}


syndrome, including depression, anorexia, watery diarrhea, tachycardia, bradypnea, pyrexia, and decreased $\mathrm{pH}$ value of rumen liquid. By contrast, the clinical manifestations of the heifers in the control group were normal. The heart rate of the heifers in the treatment group significantly increased $(P<0.05)$ relative to the baseline (time 0 ) at $6-60 \mathrm{~h}$ and to that of the heifers in the control group at 12 and $36-60 \mathrm{~h}$. The rectal temperature of the heifers in the treatment group significantly increased $(P<$ $0.05)$ relative to the baseline at 12 and $24-60 \mathrm{~h}$ and to that of the heifers in the control group at $12-60 \mathrm{~h}$. The respiratory rate of the heifers in the treatment group significantly decreased $(P<0.05)$ relative to the baseline at $18-48 \mathrm{~h}$. The $\mathrm{pH}$ value of rumen liquid of the heifers in the treatment group significantly decreased $(P<$ $0.05)$ relative to the baseline at $6-72 \mathrm{~h}$ and to that of the heifers in the control group at 6-60 h. The data on physiological parameters are illustrated in Figure 1.

In the treatment group, the heifers' locomotion scores were 1 (normal) at $0 \mathrm{~h}$, and they initially developed signs of lameness at $36 \mathrm{~h}$. At $72 \mathrm{~h}$, the locomotion scores of all heifers were $\geq 2$, and each of them had a consecutive painful reaction in the same claw. By contrast, in the control group, the heifers' locomotion scores were 1 at selected time points and did not exhibit consecutive painful reactions in hoof testing examination.

\section{Gene Expressions of Laminar MMPs in Bovine Laminitis}

The gene expressions of laminar MMP-2 $(P<0.01)$ and MMP-9 $(P<0.05)$ significantly increased in the treatment group relative to those in the control group (Table 3, Figure 2).

\section{Gene Expressions of Laminar ADAMs in Bovine Laminitis}

No change in the gene expressions of laminar ADAM-10 and ADAM-17 was observed in the treatment group relative to that in the control group (Table 3, Figure 3).

\section{Gene Expressions of Laminar ADAMTs in Bovine Laminitis}

The gene expressions of laminar ADAMTS-4 $(P<0.001)$ and ADAMTS-5 $(P<0.01)$ significantly increased in the treatment group relative to those in the control group. No change was observed in the gene expression of laminar ADAMTS-1 (Table 3, Figure 4).

\section{Gene Expressions of Laminar TIMPs in Bovine Laminitis}

The gene expressions of laminar TIMP-2 significantly decreased $(P<0.001)$ in the treatment group relative to those in the
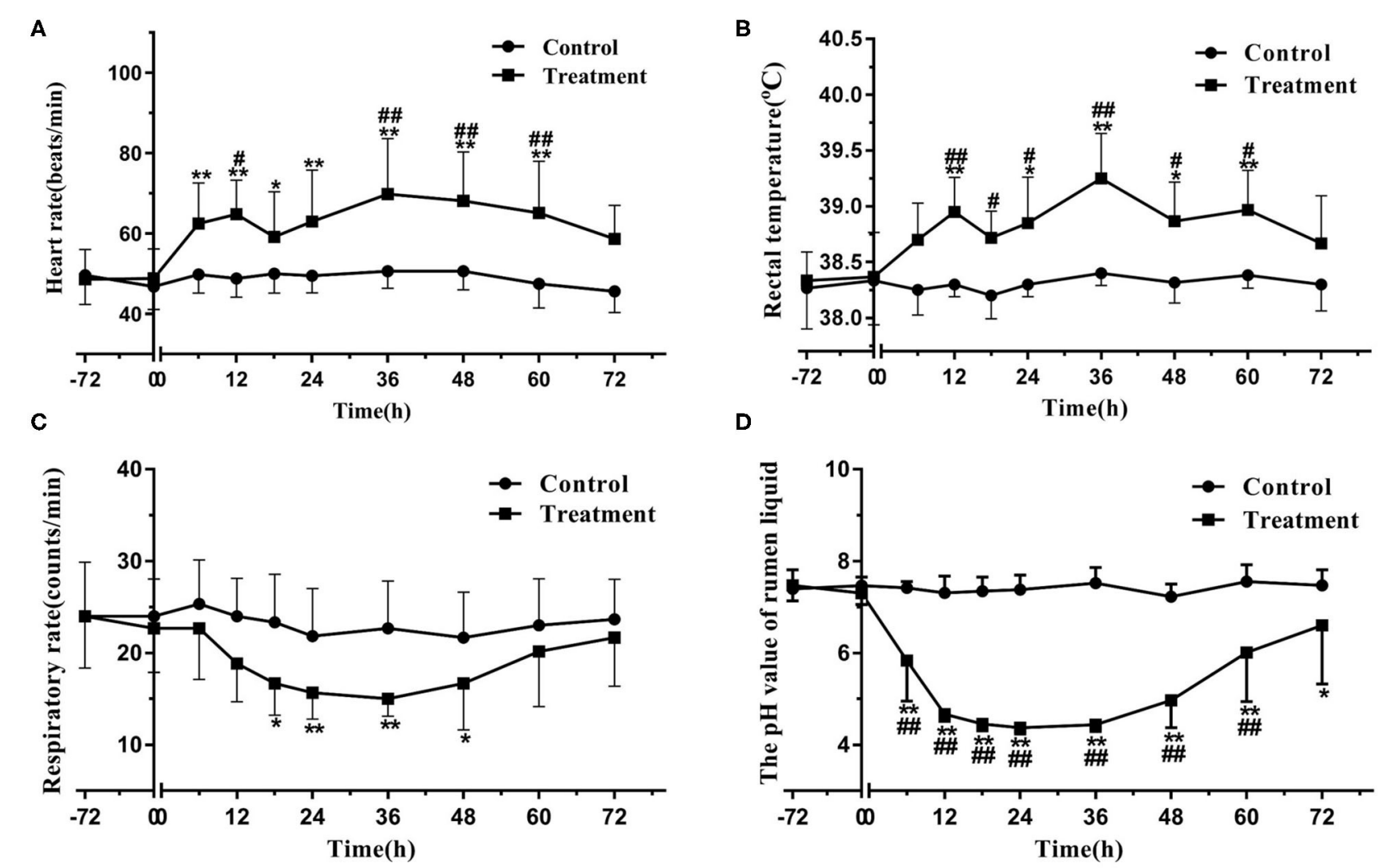

FIGURE 1 | Changes in heart rate (A), rectal temperature (B), respiratory rate (C), and pH value of rumen liquid (D) in the heifers with oligofructose-induced laminitis. Within a time point, the values of the treatment group significantly differed from those of the control group, indicated as \# $P<0.05$ and $\# \# P<0.01$; within the treatment group, the values of distinct time points significantly differed from the baseline value (time 0 ), indicated as * $P<0.05$ and ${ }^{* \star} P<0.01$. 
control group. No change was observed in the gene expressions of laminar TIMP-1 and TIMP-3 (Table 3, Figure 5).

\section{DISCUSSION}

Considering the important role of MPs and TIMPs in BM destruction and separation of equine laminitis, numerous researchers inferred that disordered MP events may also contribute to bovine laminitis $(18,19)$. However, no study has reported this event thus far. Thus, we established a previously described (and reliable) bovine laminitis model, and then

TABLE 3 | Fold changes in the gene expressions of laminar metalloproteases and their inhibitors in the heifers with oligofructose-induced laminitis.

\begin{tabular}{lcc}
\hline Metalloprotease & \multicolumn{1}{c}{ Fold change (mean \pm SD) } & P-value \\
\hline Matrix metalloprotease (MMP) & \\
MMP-2 & $4.81 \pm 2.20^{\uparrow}$ & 0.0082 \\
MMP-9 & $3.46 \pm 3.89 \uparrow$ & 0.0139 \\
A disintegrin and metalloprotease (ADAM) & \\
ADAM-10 $\quad 0.86 \pm 0.37^{\mathrm{NS}}$ & 0.3901 \\
ADAM-17 & $1.03 \pm 0.58^{\mathrm{NS}}$ & 0.9147 \\
A disintegrin and metalloprotease with thrombospondin motifs (ADAMTS) \\
ADAMTS-1 $\quad 1.18 \pm 0.57^{\mathrm{NS}}$ & 0.4983 \\
ADAMTS-4 & $9.20 \pm 2.1{ }^{\uparrow}$ & 0.0002 \\
ADAMTS-5 & $4.90 \pm 1.31^{\uparrow}$ & 0.0022 \\
Tissue inhibitors of metalloprotease (TIMP) & \\
TIMP-1 & $0.81 \pm 0.30^{\mathrm{NS}}$ & 0.1866 \\
TIMP-2 & $0.43 \pm 0.10 \downarrow$ & $<0.0001$ \\
TIMP-3 & $0.73 \pm 0.37^{\mathrm{NS}}$ & 0.1303 \\
\hline
\end{tabular}

Values displayed are from fold changes in the treatment group relative to those in the control group; NS, non-significant change in values; $\uparrow$, significant increase in values; $\downarrow$, significant decrease in values. determined the gene expression of representative MPs and their endogenous inhibitors. To our knowledge, the present study is the first to investigate and characterize gene-level changes of MP events in OF-induced bovine laminitis.

Bovine laminitis was initially described as a diffuse aseptic inflammation of the dermal lamellae of the claw (30). Afterward, researchers proposed a broader definition of bovine laminitis as a systemic disease with local manifestations in the claw (8). In clinical practice, bovine laminitis is typically secondary to severe systemic inflammatory diseases, especially rumen acidosis, septic pleuropneumonia, metritis, etc. We adopted the OF-induced laminitis model in this study because it mimics well the practical conditions in modern dairy farms, where high-energy feeding often leads to the occurrence of rumen acidosis in dairy cows (31). Moreover, this model could exhibit the typical characteristic pathophysiological and histological changes as in clinical cases of bovine laminitis. Besides, this model was easier to operate and successfully establish experimental bovine laminitis, and had better repeatability than other induction models (10).

An overloaded ingestion of OF (a type of non-structural carbohydrate), which can rapidly reduce the $\mathrm{pH}$ of rumen liquid, compromises intestinal barrier functions and results in the death of numerous Gram-negative bacteria. The free lipopolysaccharide (LPS) translocates from the digestive tract into the peripheral circulation (32), leading to systemic inflammatory responses and multiple organ damage, including laminitis (33), rumenitis (34), and synovitis (35).

Lamellae tissues are critical for maintaining proper P3 orientation and transferring mostly mechanical forces to the hoof because they link the P3 to the hoof capsule (36). Lamellae consist of interconnected epidermal lamellae and dermal lamellae, as well as a contact interface that is BM. BM destruction and detachment are the characteristic histological lesions that contribute to the failure of epidermal attachment in bovine laminitis (11). Numerous complex components are present around BM,

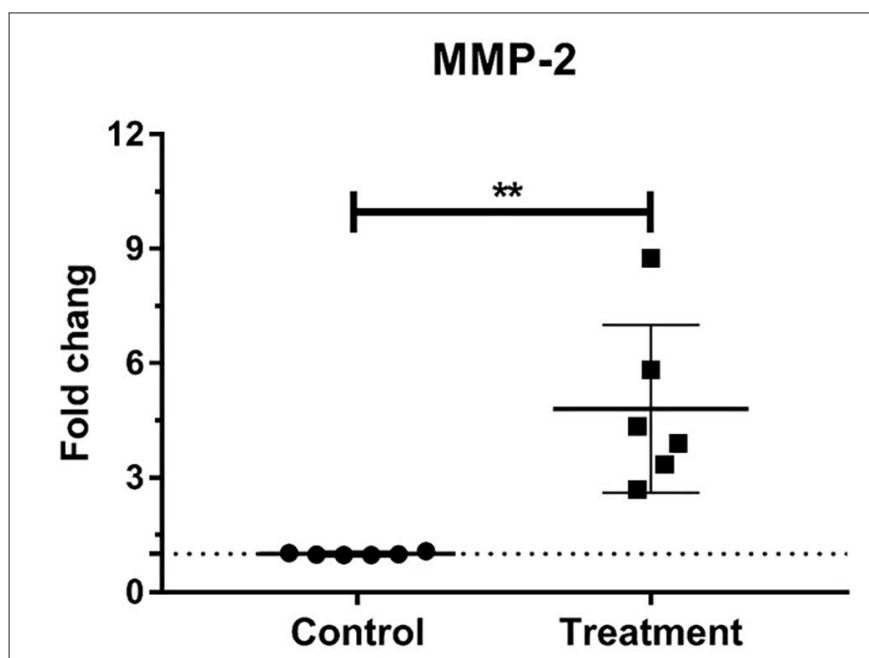

\section{MMP-9}

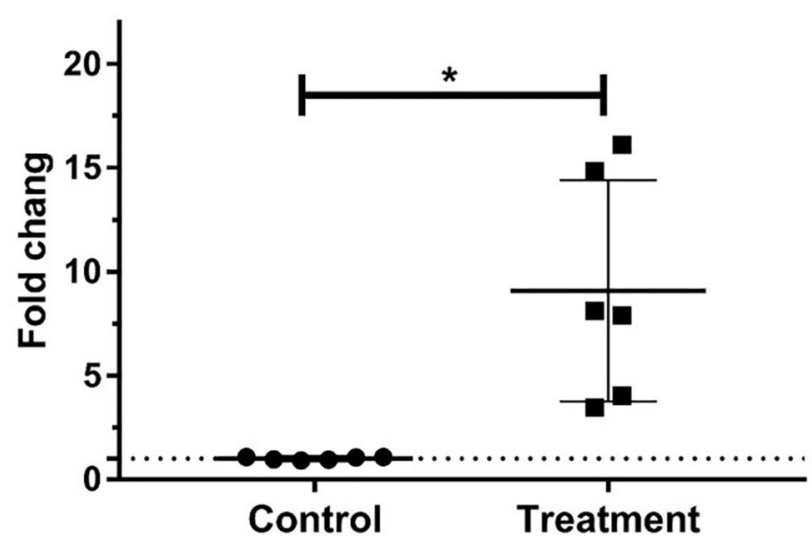

FIGURE 2 | Mean fold changes in MMP-2 and MMP-9 mRNA expression following oligofructose-overload administration in dairy heifers. Significant increases in the treatment group relative to those in the control group, indicated as ${ }^{\star} P<0.05$ and ${ }^{\star \star} P<0.01$. 

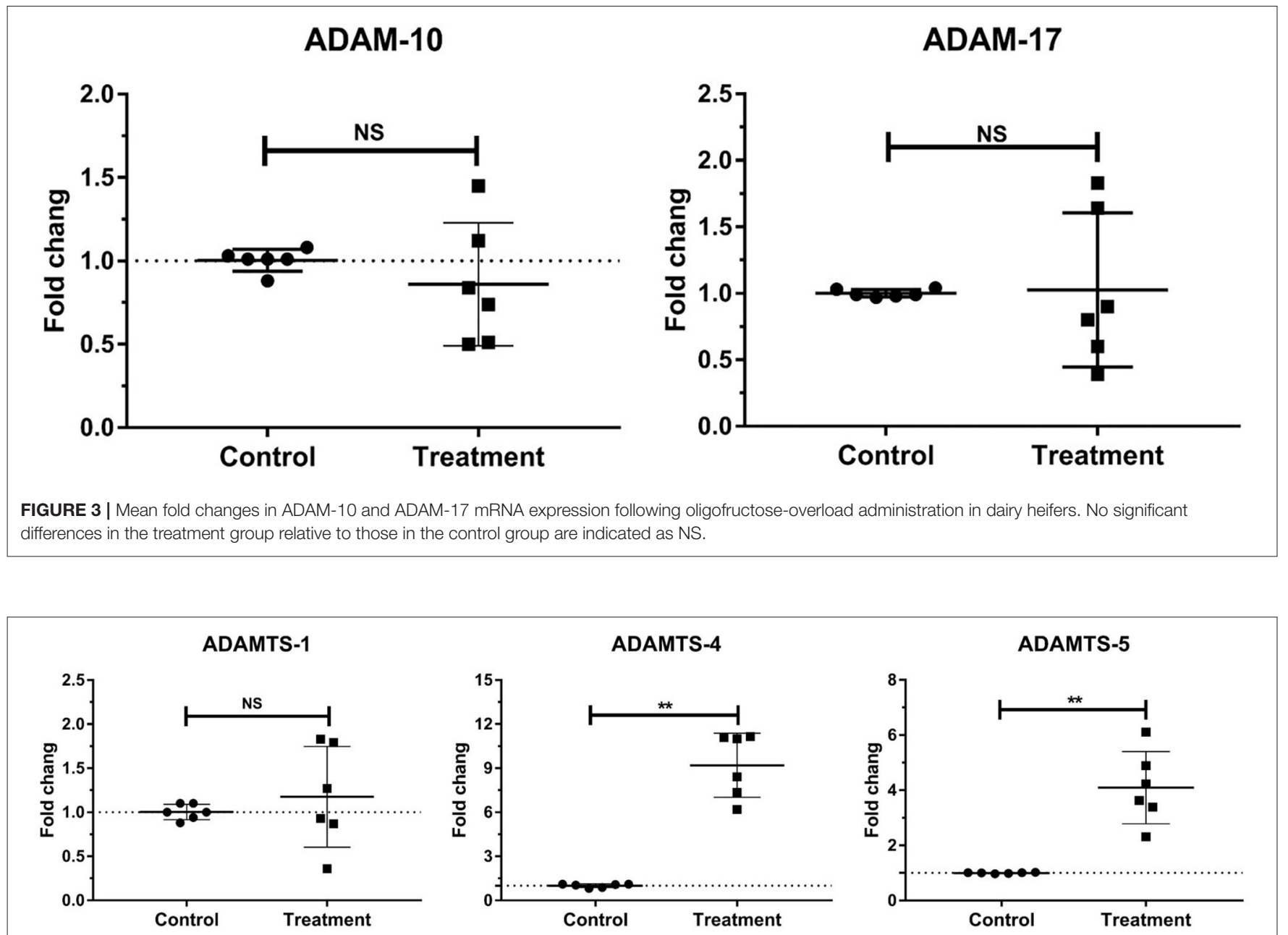

FIGURE 4 | Mean fold changes in ADAMTS-1, ADAMTS-4, and ADAMTS-5 mRNA expression following oligofructose-overload administration in dairy heifers. The values of the treatment group significantly differed from those of the control group values, indicated as ${ }^{\star \star} P<0.01$; no significant differences indicated as NS.

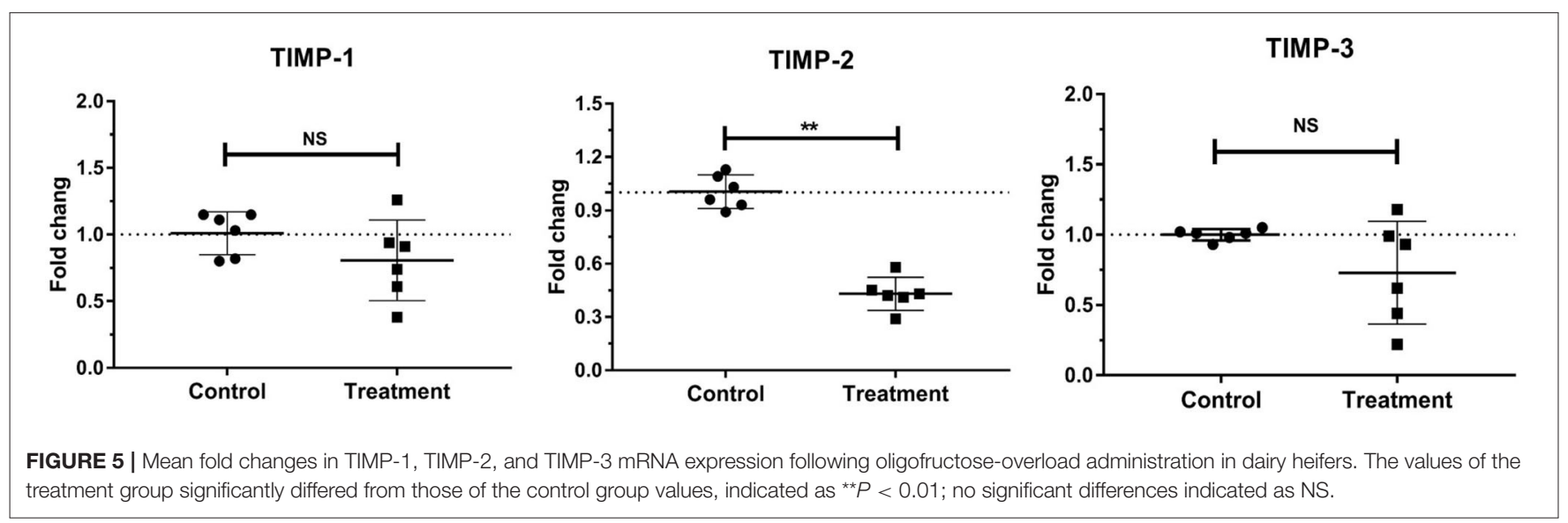

including collagen, laminin, MPs, versican, aggrecan, and keratin (37). MPs are the primary proteases involved in ECM remodeling under physiological and pathological conditions $(38,39)$. Thus, we can reasonably speculate that disordered proteolytic events involving MPs and other components may occur in the progression of bovine laminitis. 
In our published literature, we have already proved that the bovine laminitis was successfully established using the OFinduced model, and laminitic heifers developed characteristic histological lesions in the lamellae, including BM destruction and detachment, stretching of epidermal lamellae and changes in basal cell morphology (33). Herein, we utilized the same batch of lamellae tissue as that literature, then conducted further gene-level measurement of representative MPs and TIMPs.

In the present study, the gene expression of laminar MMP2 and MMP-9 significantly increased in the OF-induced heifers. These results were consistent with those of multiple studies on equine laminitis $(15,16)$ and those of a study on dairy cows with sole ulcer (a type of laminitis-related lesion) (19), suggesting that these MMPs may also be deeply implicated in bovine laminitis.

One of the primary mechanisms of MMP-2/MMP-9 regulation is at the level of transcription $(20,39)$, especially they could be induced response to multiple stimuli, including proinflammatory cytokines, transforming growth factors, and LPS (40). In our previous studies, we utilized the same batch of lamellae samples as this study, and reported the increased gene expression of multiple proinflammatory mediators (33). These results may provide a possible explanation to the increases in MMP-2 and MMP-9 expression observed in the present study. Moreover, several signaling pathways, such as nuclear factor kappa B, mitogen-activated protein kinases, and signal transducers and activators of transcription, also participate in the transcriptional regulation of MMPs (41).

Generally, the transcriptional-level MMP-2 and MMP9 are important basis for further protein-level expression of proenzyme MMP-2 (proMMP-2) and proenzyme MMP-9 (proMMP-9) as well as MMP-2 and MMP-9 $(20,39)$. Both MMP2 (gelatinase-A) and MMP-9 (gelatinase-B) play a key role in the remodeling of collagenous ECM. MMP-9 can especially degrade denatured collagen and gelatin, native type I collagen of ECM, and native type IV collagen of BM, as well as laminin components in lamellae (42). By comparison, MMP-2 can degrade distinct native collagens and laminin, as well as aggrecan, fibronectin, and vitronectin in ECM (43).

MMP-2 and MMP-9 can be expressed by various cell types, such as endothelial cells, fibroblasts, keratinocytes, and monocytes in the case of MMP-2, and granulocytes, macrophages, and osteoclasts in the case of MMP-9 (39). In equine laminitis, the concentration of laminar proMMP-9 is strongly correlated with neutrophil migration into the lamellae and myeloperoxidase (MPO) content, suggesting that proMMP9 may be released from or induced by neutrophils. By contrast, the concentration of proMMP-2 has no correlation with MPO content and proMMP-9, suggesting that proMMP-2 may be expressed by innate cells in the lamellae rather than by migrant inflammatory leukocytes (44). Using the same samples, we found that an increase in MPO content also has a strong positive correlation with an increase in proMMP-9 rather than in proMMP-2 in bovine laminitis. These results indicated that proMMP-9 may be released from migrated neutrophils, whereas proMMP-2 may be expressed by innate cells in the lamellae, such as fibroblasts and keratinocytes.
The conversion from proMMP-9 to MMP-9 primarily involves three pathways: proteolytic removal of proMMP-9 propeptide, binding of proMMP-9 to active substrates, and oxidative modification of proMMP-9 (45). Meanwhile, proMMP2 is converted to MMP-2 via two pathways: induction by the MT-MMP/TIMP-2 complex (but this way has been suspected in equine laminitis); and processing by neutrophil-derived proteases, especially elastase, cathepsin-G, and proteinase- 3 (46). From previous studies of equine laminitis, only inactive proMMP-9 and MMP-2 were increased in the lamellae of OFinduced experimental model as well as naturally clinical cases (44, 47). More protein-level studies (e.g., using native zymography technology) should be performed to confirm the changes of MMP-9/MMP-2 activity in these samples.

Aside from gelatinases, researchers studying laminitis also focus on ADAMs, a family of membrane-anchored enzymes, because they can regulate distinct cellular functions, such as proteolysis, cell adhesion and migration, and cellular signaling (48). ADAM-10 and ADAM-17 are regarded as important research hotspots because of their vital roles in immunity and inflammatory response (49).

In the present study, the gene expressions of laminar ADAM10 and ADAM-17 were stable in the heifers with OF-induced laminitis relative to those in the control group. Previous studies obtained similar results in OF-induced and naturally acquired equine laminitis (15). Notably, these results were unexpected because ADAM-10 and ADAM-17 reportedly participate in nearly all central events of inflammation response, including myelopoiesis, inflammatory cytokine production, migration, phagocytosis, and antigen-presenting functions (21). Using the same samples, we reported in a previous study that the gene expression of laminar tumor necrosis factor- $\alpha$ is stable in bovine laminitis (33), maybe it is a reasonable explanation for the stable ADAM-17 gene expression observed herein because ADAM17 can regulate the cleavage of membrane-bound TNF into soluble active $\operatorname{TNF}(50,51)$. Another possible explanation to these results is that the low level of inflammatory response actually occurred in this laminitis model: the OF-induced heifers experienced transient fever and tachycardia and then their lameness symptoms eventually disappeared, indicating that this model induced a relatively mild laminitis $(9,10)$.

ADAMTS, the secreted-type metalloprotease of the ADAMTS superfamily, has catalytic activity and participates in ECM remodeling because its substrates are the primary structural components of ECM $(52,53)$. Furthermore, ADAMTS protease has the propensity to adhere to the pericellular matrix of basal cells, thereby affecting cell adhesion and survival (54). Thus, several researchers speculate that ADAMTS may greatly contribute to the pathogenesis of bovine laminitis $(16,55)$.

ADAMTS-1 was the first cloned protease in the ADAMTS superfamily (56). This protease is involved in regulating organ morphology and functions, vascular biology, and degenerative intervertebral disc diseases similar to degenerative osteoarthritis (OA) (57-59). However, in the present study, the gene expression of laminar ADAMTS-1 was stable, suggesting that it may not participate in the development of this disease. 
By contrast, the gene expressions of laminar ADAMTS4 and ADAMTS-5 significantly increased in the heifers with OF-induced laminitis. Using the same sample, we previously reported increased laminar IL-1 and IL-6 gene expression (33). An increase in the gene expression of these interleukins may induce increases in ADAMTS-4 and ADAMTS-5 expression because IL-1 and IL-6 reportedly contribute to the induction of ADAMTS-4 and ADAMTS-5 in the cartilage (60). Moreover, ADAMTS-4 and ADAMTS-5 purportedly can affect tissue growth and upkeep, vascular biology, and OA progression (61). They are considered as the major aggrecanases in the development of OA because they can degrade the structural aggrecans of cartilage ECM. With regard to bovine laminitis, aside from aggrecans, multiple other glycoproteins and proteoglycans also exist around BM and basal epidermal cells, such as versican, brevican, and biglycan $(37,62,63)$. Notably, these components can also be cleaved by ADAMTS- 4 and ADAMTS-5 (64).

Similar results were obtained by a previous study on equine laminitis, which indicated that changes in ADAMTS4 and versican may arise from physiological changes in basal epidermal cells (55). These changes eventually lead to the separation between BM and epidermal lamellae. On the basis of evident changes in morphology and biological condition of basal epidermal cells, the separation between BM and epidermal lamellae, the loss of glycoproteins and proteoglycans around $\mathrm{BM}(12,26)$, and the increase in gene expressions of ADAMTS-4 and ADAMTS-5 and their special biological properties, we hypothesize that ADAMTS-4 and ADAMTS-5 play a key role in bovine laminitis. Additional direct evidence is needed to verify our hypothesis. In follow-up studies, these valuable parameters, including the ADAMTS-4 and ADAMTS5, their substrates (e.g., aggrecan and versican), and the cleaved fragments of their substrates, should be detected at the protein level.

TIMPs are small endogenous proteins that contain an $\mathrm{N}$ terminal inhibitory domain that binds to the active domains of MMPs, ADAMs, and ADAMTSs. Moreover, TIMPs inhibit the activities of these MPs. Therefore, TIMPs are the vital regulators of ECM turnover, tissue remodeling, and cellular signaling (65). Aside from inhibiting MP activities, TIMPs also perform various biological activities, such as promoting cell proliferation, antiangiogenic activity, and synaptic plasticity activities associated with motor dysfunction (66). The TIMP family has four members, of which three were selected in the present study. TIMP-3 exhibited the broadest inhibition array of MPs because it could inhibit multiple members of the ADAM and ADAMTS families (Table 4).

The present study observed that the gene expression of laminar TIMP-2 significantly decreased in the heifers with OFinduced laminitis relative to that in the control group. By contrast, the gene expressions of TIMP-1 and TIMP-3 were stable, suggesting that TIMP-2 may specifically participate in the pathogenesis of bovine laminitis. Recently, our research group finished using the reverse zymography assays to determine the activity of TIMP-1 and TIMP-2, finally found the reduced protein-level TIMP-2 in the OF-induced laminitic heifers $(\mathrm{Li}$,
TABLE 4 | Summary of inhibition relationships between the selected TIMPs and MPs in the present study.

\begin{tabular}{llll}
\hline Property & TIMP-1 & TIMP-2 & TIMP-3 \\
\hline proMMP interaction & proMMP-9 & proMMP-2 & proMMP-2, 9 \\
MMP inhibition & MMP-9 & MMP-2, 9 & MMP-2, 9 \\
Other MP inhibition & ADAM-10 & & ADAM-10, 17; ADAMTS-1, 4, 5
\end{tabular}

TIMP, tissue inhibitors of metalloproteinase; MP, metalloproteinase; MMP, matrix metalloproteinase; ADAM, A disintegrin and metalloproteinase; ADAMTS, A disintegrin and metalloproteinase with thrombospondin motifs.

unpublished results). This finding may possibly explain the increases in MMP-2 and MMP-9 activities, because reduced TIMP-2 could decrease its inhibition to MMP-2 and MMP-9 activities. As mentioned previously, proMMP-2 is converted to MMP-2 via the induction of the MT-MMP/TIMP-2 complex. However, in consideration of the decrease in TIMP-2 expression and the increase in MMP-2 expression, this pathway may be not the primary route in bovine laminitis. Other studies reported similar findings (16).

A decrease in the gene expression of laminar TIMP-2 was also found in horses with OF-induced laminitis and dairy cows with sole ulcer $(15,19)$. This result suggested that TIMP-2 may play a similar role in the laminitis of distinct animal species. Previous studies reported that a decrease in TIMP-2 expression initiates the induction of equine laminitis as observed in the initial period of disease progression (16). Accordingly, researchers regard TIMP-2 as a potential therapeutic target for laminitis.

Stable gene expressions of laminar TIMP-1and TIMP-3 were also observed in OF-induced equine laminitis (15). Given the stability of ADAM-10 and ADAM-17 expression, the stable gene expressions of TIMP-1 and TIMP-3 seem reasonable because they are potent inhibitors that regulate the induction and activation of these two ADAMs $(21,67)$. Although TIMP-3 can finely inhibit the proteolytic activities of ADAMTS- 4 and ADAMTS-5 $(68,69)$, the present study indicated that the stable TIMP-3 expression evidently had a weak effect on the increase in ADAMTS-4 and ADAMTS-5 expression and BM destruction, suggesting that this inhibitor does not play an important role in the development and progression of this disease.

In conclusion, this study reported the gene expressions of three classes of laminar MPs and their inhibitors in the heifers with OF-induced laminitis. We found that the gene expressions of lamellar gelatinase (MMP-2 and MMP-9), ADAMTs (ADAMTS-4 and ADAMTS-5), and an endogenous inhibitor (TIMP-2) was disordered in laminitic heifers. These results indicated that the gene-level imbalanced condition of MPs and their inhibitors may be the basic cause for the BM detachment from epidermal lamellae. This study contributes to our understanding of gene-level MP events in bovine laminitis. At the same time, more detailed protein-level studies would be needed to further clarify the roles of MPs and TIMPs in the pathogenesis of bovine laminitis, especially to MMP-2, MMP-9, ADAMTS-4, ADAMTS-5, TIMP-2 as well as related substrates (e.g., aggrecan and versican). 


\section{DATA AVAILABILITY STATEMENT}

The original contributions presented in the study are included in the article/Supplementary Material, further inquiries can be directed to the corresponding author.

\section{ETHICS STATEMENT}

The animal study was reviewed and approved by Animal Ethics Committee of the Northeast Agricultural University (Harbin, Heilongjiang, China) (Permission number: SRM-13).

\section{AUTHOR CONTRIBUTIONS}

JD designed and performed this study, analyzed data, and wrote the manuscript. MS, LW, DQ, ZT, and MH joined the animal experiments and contributed to the seminar discussions. TL, J-tZ, and HW provided valuable guidances. All authors approved the final version of the manuscript.

\section{FUNDING}

This study was funded by the National Key R \& D Program of China (Project No. 2017YFD0502200) and Heilongjiang Provincial Funding for National Subjects (GX18B023).

\section{REFERENCES}

1. Huxley JN. Lameness in cattle: an ongoing concern Introduction. Vet J. (2012) 193:610-1. doi: 10.1016/j.tvjl.2012.06.039

2. Dolecheck K, Bewley J. Animal board invited review: dairy cow lameness expenditures, losses and total cost. Animal. (2018) 12:1462-74. doi: 10.1017/S1751731118000575

3. Randall LV, Green MJ, Huxley JN. Use of statistical modelling to investigate the pathogenesis of claw horn disruption lesions in dairy cattle. Vet J. (2018) 238:41-8. doi: 10.1016/j.tvjl.2018.07.002

4. Boosman R, Nemeth F, Gruys E. Bovine laminitis: clinical aspects, pathology and pathogenesis with reference to acute equine laminitis. Vet Q. (1991) 13:163-71. doi: 10.1080/01652176.1991.9694302

5. Vermunt J. "Subclinical” laminitis in dairy cattle. N Z Vet J. (1992) 40:1338. doi: 10.1080/00480169.1992.35718

6. Alvergnas $M$, Strabel $T$, Rzewuska K, Sell-Kubiak E. Claw disorders in dairy cattle: effects on production, welfare and farm economics with possible prevention methods. Livest Sci. (2019) 222:54-64. doi: 10.1016/j.livsci.2019.02.011

7. Potterton SL, Bell NJ, Whay HR, Berry EA, Atkinson OCD, Dean RS, et al. A descriptive review of the peer and non-peer reviewed literature on the treatment and prevention of foot lameness in cattle published between 2000 and 2011. Vet J. (2012) 193:612-6. doi: 10.1016/j.tvjl.2012.06.040

8. Greenough PR. Bovine Laminitis and Lameness: A Hands on Approach. Philadelphia, PA: Elsevier Health Sciences (2007).

9. Thoefner M, Pollitt C, Van Eps A, Milinovich G, Trott D, Wattle $\mathrm{O}$, et al. Acute bovine laminitis: a new induction model using alimentary oligofructose overload. J Dairy Sci. (2004) 87:2932-40. doi: 10.3168/jds.S0022-0302(04)73424-4

10. Danscher AM, Enemark JMD, Telezhenko E, Capion N, Ekstrom CT, Thoefner MB. Oligofructose overload induces lameness in cattle. J Dairy Sci. (2009) 92:607-16. doi: 10.3168/jds.2008-1271

11. Thoefner MB, Wattle O, Pollitt CC, French KR, Nielsen SS. Histopathology of oligofructose-induced acute laminitis in heifers. J Dairy Sci. (2005) 88:277482. doi: 10.3168/jds.S0022-0302(05)72957-X

\section{ACKNOWLEDGMENTS}

Firstly, we must sincerely thank assistant editor, TS, although she told us not to thank her in any way, because she really imparted much knowledge on histology, and gave us generous help and careful guidance. Thanks very much! Then, sincere thanks to the two reviewers, through your detailed statements, you demonstrated your knowledge on laminitis. It's a good chance to learn from you, especially to the second reviewer. Sincere thanks for your careful reviewing and for providing us with valuable guidance, as well as good suggestions for the future studies. We sincerely wish these three professors keep healthy and happy forever. Finally, we thank professor, Li (nEAU) and Prof. Zhao (HMU) for explaining the histological lesions of lamellae two groups, and thank Dr. Yansong Ge, Dr. Qianzhen Zhang, Master Shuaichen Li, Master Xianhao Zhang, Master Yuepeng Li, Master Qiaozhi Song, and Master Lihong Jiang for their assistance in the study. We sincerely thank you for all of your help.

\section{SUPPLEMENTARY MATERIAL}

The Supplementary Material for this article can be found online at: https://www.frontiersin.org/articles/10.3389/fvets. 2020.597827/full\#supplementary-material

12. Mendes HM, Casagrande FP, Lima IR, Souza CH, Gontijo LD, Alves GE, et al. Histopathology of dairy cows' hooves with signs of naturally acquired laminitis. Pesquisa Veterinaria Brasileira. (2013) 33:613-9. doi: 10.1590/S0100-736X2013000500011

13. Leise BS, Faleiros RR, Watts $M$, Johnson PJ, Black SJ, Belknap JK. Laminar inflammatory gene expression in the carbohydrate overload model of equine laminitis. Equine Vet J. (2011) 43:54-61. doi: 10.1111/j.2042-3306.2010.00122.x

14. Dern K, van Eps A, Wittum T, Watts M, Pollitt C, Belknap J. Effect of continuous digital hypothermia on lamellar inflammatory signaling when applied at a clinically-relevant timepoint in the oligofructose laminitis model. J Vet Int Med. (2018) 32:450-8. doi: 10.1111/jvim.15027

15. Coyne MJ, Cousin H, Loftus JP, Johnson PJ, Belknap JK, Gradil CM, et al. Cloning and expression of ADAM-related metalloproteases in equine laminitis. Vet Immunol Immunopathol. (2009) 129:0-241. doi: 10.1016/j.vetimm.2008.11.022

16. Visser MB, Pollitt CC. The timeline of metalloprotease events during oligofructose induced equine laminitis development. Equine Vet J. (2011) 44:88-93. doi: 10.1111/j.2042-3306.2011.00393.x

17. Wang L, Pawlak EA, Johnson PJ, Belknap JK, Alfandari D, Black SJ. Expression and activity of collagenases in the digital laminae of horses with carbohydrate overload-induced acute laminitis. J Vet Int Med. (2014) 28:21522. doi: $10.1111 /$ jvim. 12252

18. Almeida PE, Weber PSD, Burton JL, Tempelman RJ, Steibel JP, Zanella AJ. Gene expression profiling of peripheral mononuclear cells in lame dairy cows with foot lesions. Vet Immunol Immunopathol. (2007) 120:0245. doi: 10.1016/j.vetimm.2007.06.028

19. O’Driscoll K, McCabe M, Earley B. Differences in leukocyte profile, gene expression and metabolite status of dairy cows with or without sole ulcers. J Dairy Sci. (2015) 98:1685-95. doi: 10.3168/jds.201 4-8199

20. Fanjul-Fernández M, Folgueras AR, Cabrera S, López-Otín C. Matrix metalloproteinases: evolution, gene regulation and functional analysis in mouse models. Biochim Biophys Acta. (2010) 1803:3. doi: 10.1016/j.bbamcr.2009.07.004 
21. Lambrecht BN, Vanderkerken M, Hammad H. The emerging role of ADAM metalloproteinases in immunity. Nat Rev Immunol. (2018) 18:74558. doi: 10.1038/s41577-018-0068-5

22. Mead TJ, Apte SS. ADAMTS proteins in human disorders. Mat Biol. (2018) 71-72:225-39. doi: 10.1016/j.matbio.2018.06.002

23. Masciantonio MG, Lee CKS, Arpino V, Mehta S, Gill SE. The balance between metalloproteinases and timps: critical regulator of microvascular endothelial cell function in health and disease. Prog Mol Biol Transl Sci. (2017) 147:10131. doi: 10.1016/bs.pmbts.2017.01.001

24. Edmonson A, Lean I, Weaver L, Farver T, Webster G. A body condition scoring chart for Holstein dairy cows. J Dairy Sci. (1989) 72:6878. doi: 10.3168/jds.S0022-0302(89)79081-0

25. Sprecher D, Hostetler D, Kaneene J. A lameness scoring system that uses posture and gait to predict dairy cattle reproductive performance. Theriogenology. (1997) 47:1179-87. doi: 10.1016/S0093-691X(97)00098-8

26. Danscher AM, Toelboell TH, Wattle O. Biomechanics and histology of bovine claw suspensory tissue in early acute laminitis. J Dairy Sci. (2010) 93:53-62. doi: 10.3168/jds.2009-2038

27. Abdelmegeid MK, Vailati-Riboni M, Alharthi A, Batistel F, Loor JJ. Supplemental methionine, choline, or taurine alter in vitro gene network expression of polymorphonuclear leukocytes from neonatal Holstein calves. J Dairy Sci. (2017) 100:3155-65. doi: 10.3168/jds.2016-12025

28. Li S, Ding J, Jiang L, Hayat MA, Zhang J. Dynamic ROS production and gene expression of heifers blood neutrophil in a oligofructose overload model. Front Vet Sci. (2020) 7:211. doi: 10.3389/fvets.2020.00211

29. Pfaffl WM. A new mathematical model for relative quantification in real-time RT-PCR. Nucleic Acids Res. (2001) 29:e45. doi: 10.1093/nar/29.9.e45

30. Nilsson SA. Clinical, morphological and experimental studies of laminitis in cattle. Acta Vet Scand. (1963) 4:1-304.

31. Plaizier JC, Khafipour E, Li S, Gozho GN, Krause DO. Subacute ruminal acidosis (SARA), endotoxins and health consequences. Animal Feed Ence Technol. (2012) 172:9-21. doi: 10.1016/j.anifeedsci.2011.12.004

32. Khafipour E, Krause DO, Plaizier JC. A grain-based subacute ruminal acidosis challenge causes translocation of lipopolysaccharide and triggers inflammation. J Dairy Ence. (2009) 92:1060-70. doi: 10.3168/jds.2008-1389

33. Ding J, Li S, Jiang L, Li Y, Zhang X, Song Q, et al. Laminar inflammation responses in the oligofructose overload induced model of bovine laminitis. Front Vet Sci. (2020) 7:351. doi: 10.3389/fvets.2020.00351

34. Zhao C, Liu G, Li X, Guan Y, Wang Y, Yuan X, et al. Inflammatory mechanism of Rumenitis in dairy cows with subacute ruminal acidosis. BMC Vet Res. (2018) 14:1-8. doi: 10.1186/s12917-018-1463-7

35. Hidalgo AI, Carretta MD, Alarcon P, Manosalva C, Muller A, Navarro $\mathrm{M}$, et al. Pro-inflammatory mediators and neutrophils are increased in synovial fluid from heifers with acute ruminal acidosis. BMC Vet Res. (2019) 15:225. doi: 10.1186/s12917-019-1974-x

36. RaBer M, Lischer CJ, Geyer H, Ossent P. The bovine digital cushion - a descriptive anatomical study. Vet J. (2004) 167:25864. doi: 10.1016/S1090-0233(03)00053-4

37. Tomlinson DJ, Mulling $\mathrm{CH}$, Fakler TM. Invited review: formation of keratins in the bovine claw: roles of hormones, minerals, and vitamins in functional claw integrity. J Dairy Sci. (2004) 87:797-809. doi: 10.3168/jds.S0022-0302(04)73223-3

38. Khokha R, Murthy A, Weiss A. Metalloproteinases and their natural inhibitors in inflammation and immunity. Nat Rev Immunol. (2013) 13:64965. doi: 10.1038/nri3499

39. Apte SS, Parks WC. Metalloproteinases: a parade of functions in matrix biology and an outlook for the future. Mat Biol. (2015) 44-46:16. doi: 10.1016/j.matbio.2015.04.005

40. Yan C, Boyd DD. Regulation of matrix metalloproteinase gene expression. $J$ Cell Physiol. (2007) 211:19-26. doi: 10.1002/jcp.20948

41. Vincenti MP, Brinckerhoff CE. Signal transduction and cell-type specific regulation of matrix metalloproteinase gene expression: can MMPs be good for you? J Cell Physiol. (2007) 213:355-64. doi: 10.1002/jcp.21208

42. Gomis-Rüth FX. Catalytic domain architecture of metzincin metalloproteases. J Biol Chem. (2009) 284:15353-7. doi: 10.1074/jbc.R800069200

43. Le NT, Xue M, Castelnoble LA, Jackson CJ. The dual personalities of matrix metalloproteinases in inflammation. Front Biosci. (2007) 12:147587. doi: $10.2741 / 2161$
44. Loftus JP, Johnson PJ, Belknap JK, Pettigrew A, Black SJ. Leukocytederived and endogenous matrix metalloproteinases in the lamellae of horses with naturally acquired and experimentally induced laminitis. Vet Immunol Immunopathol. (2009) 129:221-30. doi: 10.1016/j.vetimm.2008.11.003

45. Tobar N, Villar V, Santibanez JF. ROS-NFk? mediates TGF- $\beta 1$ induced expression of urokinase-type plasminogen activator, matrix metalloproteinase-9 and cell invasion. Mol Cell Biochem. (2010) 340:195-202. doi: 10.1007/s11010-010-0418-5

46. Shamamian P, Schwartz JD, Pocock BJZ, Monea S, Whiting D, Marcus SG et al. Activation of progelatinase A (MMP-2) by neutrophil elastase, cathepsin $\mathrm{G}$, and proteinase-3: a role for inflammatory cells in tumor invasion and angiogenesis. J Cell Physiol. (2001) 189:197-206. doi: 10.1002/jcp.10014

47. Black SJ, LeWang, Pawlak E, Zhang F, Loftus J, Alfandari D. Role of proteases in laminitis. In: Belknap JK, Geor RJ, editors. Equine Laminitis. Hoboken, NJ: JohnWiley \& Sons, Inc (2017). p. 115-33. doi: 10.1002/9781119169239

48. Saha N, Robev D, Himanen JP, Nikolov DB. ADAM proteases: emerging role and targeting of the non-catalytic domains. Cancer Lett. (2019) 467:507. doi: 10.1016/j.canlet.2019.10.003

49. Matthews AL, Noy PJ, Reyat JS, Tomlinson MG. Regulation of A disintegrin and metalloproteinase (ADAM) family sheddases ADAM10 and ADAM17: the emerging role of tetraspanins and rhomboids. Platelets. (2017) 28:33341. doi: 10.1080/09537104.2016.1184751

50. Schwarz J, Schmidt S, Will O, Koudelka T, Kohler K, Boss M, et al. Pololike Kinase 2, a novel ADAM17 signaling component, regulates tumor necrosis factor $\alpha$ ectodomain shedding. J Biol Chem. (2014) 289:308093. doi: $10.1074 /$ jbc.M113.536847

51. Maney SK, Mcilwain DR, Polz R, Pandyra AA, Sundaram B, Wolff D, et al. Deletions in the cytoplasmic domain of iRhom1 and iRhom2 promote shedding of the TNF receptor by the protease ADAM17. Sci Signal. (2015) 8:401. doi: 10.1126/scisignal.aac5356

52. Dubail J, Apte SS. Insights on ADAMTS proteases and ADAMTSlike proteins from mammalian genetics. Matrix Biol. (2015) 44-46:2437. doi: 10.1016/j.matbio.2015.03.001

53. Apte S. ADAMTS Proteases Methods and Protocols: Methods and Protocols. New York, NY: Humana (2020). doi: 10.1007/978-1-4939-9698-8

54. Cal S, López-Otín C. ADAMTS proteases and cancer. Matrix Biol. (2015) 44-46:77-85. doi: 10.1016/j.matbio.2015.01.013

55. Wang L, Pawlak E, Johnson PJ, Belknap JK, Alfandari D, Black SJ. Effects of cleavage by a disintegrin and metalloproteinase with thrombospondin motifs4 on gene expression and protein content of versican and aggrecan in the digital laminae of horses with starch gruel-induced laminitis. Am J Vet Res. (2012) 73:1047-56. doi: 10.2460/ajvr.73.7.1047

56. Kanada, N. Molecular cloning of a gene encoding a new type of metalloproteinase-disintegrin family protein with thrombospondin motifs as an inflammation associated gene. J Biol Chem. (1997) 272:55662. doi: $10.1074 / \mathrm{jbc} .272 .1 .556$

57. Shindo T, Kurihara H, Kuno K, Yokoyama H, Wada T, Kurihara Y, et al. ADAMTS-1: a metalloproteinase-disintegrin essential for normal growth, fertility, and organ morphology and function. JClin Investig. (2000) 105:134552. doi: $10.1172 /$ JCI 8635

58. Virtanen IM, Noponen N, Barral S, Karppinen J, Li H, Vuoristo MM, et al. Putative susceptibility locus on chromosome $21 \mathrm{q}$ for lumbar disc disease (LDD) in the Finnish population. J Bone Min Res. (2007) 22:7017. doi: $10.1359 /$ jbmr.070123

59. Rodriguezmanzaneque JC, Fernandezrodriguez R, Rodriguezbaena FJ, Iruelaarispe ML. ADAMTS proteases in vascular biology. Mat Biol. (2015) 44:38-45. doi: 10.1016/j.matbio.2015.02.004

60. Verma P, Dalal K. ADAMTS-4 and ADAMTS-5: key enzymes in osteoarthritis J Cell Biochem. (2011) 112:3507-14. doi: 10.1002/jcb.23298

61. Kelwick R, Desanlis I, Wheeler GN, Edwards DR. The ADAMTS (A Disintegrin and Metalloproteinase with Thrombospondin motifs) family. Genome Biol. (2015) 16:113. doi: 10.1186/s13059-015-0676-3

62. Nakamura H, Fujii Y, Inoki I, Sugimoto K, Tanzawa K, Matsuki $\mathrm{H}$, et al. Brevican is degraded by matrix metalloproteinases and aggrecanase-1 (ADAMTS4) at different sites. J Biol Chem. (2000) 275:38885-90. doi: 10.1074/jbc.M003875200

63. Hendry KAK, Knight CH, Galbraith H, Wilde CJ. Basement membrane integrity and keratinization in healthy and ulcerated bovine hoof 
tissue. J Dairy Res. (2003) 70:19-27. doi: 10.1017/S0022029902 005885

64. Gendron C, Kashiwagi M, Lim NH, Enghild JJ, Thogersen IB, Hughes CE, et al. Proteolytic activities of human ADAMTS5: comparative studies with ADAMTS-4. J Biol Chem. (2007) 282:18294-306. doi: 10.1074/jbc.M701523200

65. Brew K, Nagase H. The tissue inhibitors of metalloproteinases (TIMPs): an ancient family with structural and functional diversity. Biochim Biophys Acta. (2010) 1803:55-71. doi: 10.1016/j.bbamcr.2010.01.003

66. Arpino V, Brock M, Gill SE. The role of TIMPs in regulation of extracellular matrix proteolysis. Mat Biol. (2015) 44:24754. doi: 10.1016/j.matbio.2015.03.005

67. Shimoda M, Principe S, Jackson HW, Luga V, Fang H, Molyneux SD, et al. Loss of the Timp gene family is sufficient for the acquisition of the CAF-like cell state. Nat Cell Biol. (2014) 16:889-901. doi: 10.1038/ncb3021

68. Wayne G, Deng S, Amour A, Borman SK, Matico R, Carter HL, et al. TIMP3 Inhibition of ADAMTS-4 (Aggrecanase-1) is modulated by interactions between aggrecan and the C-terminal domain of ADAMTS-4. J Biol Chem. (2007) 282:20991-8. doi: 10.1074/jbc.M610721200

69. Troeberg L, Fushimi K, Scilabra SD, Nakamura H, Dive V, Thogersen IB, et al. The C-terminal domains of ADAMTS-4 and ADAMTS-5 promote association with N-TIMP-3. Mat Biol. (2009) 28:463-9. doi: 10.1016/j.matbio.2009.07.005

Conflict of Interest: The authors declare that the research was conducted in the absence of any commercial or financial relationships that could be construed as a potential conflict of interest.

Copyright (C) 2020 Ding, Shi, Wang, Qi, Tao, Hayat, Liu, Zhang and Wang. This is an open-access article distributed under the terms of the Creative Commons Attribution License (CC BY). The use, distribution or reproduction in other forums is permitted, provided the original author(s) and the copyright owner(s) are credited and that the original publication in this journal is cited, in accordance with accepted academic practice. No use, distribution or reproduction is permitted which does not comply with these terms. 